\title{
Assessment of the Knowledge, Attitude and Practice about Food Safety among Saudi Population in Taif
}

\author{
Ahmed Mahmoud Khalifa ${ }^{1}$, Khadiga Ahmed Ismail ${ }^{2,3 *}$, Farah Anjum Ansari ${ }^{2}$ and Hasnaa A Abouseif ${ }^{4}$ \\ ${ }^{1}$ Forensic and Toxicology Department, Ain-Shams University, Egypt \\ ${ }^{2}$ Medical Laboratory Department, Taif University, Saudi Arabia \\ ${ }^{3}$ Parasitology Department, Ain-Shams University, Egypt \\ ${ }^{4}$ Community Department, Ain-Shams University, Egypt
}

Received: 漹 August 11, 2018; Published: 眥 August 22, 2018

*Corresponding author: Khadiga Ahmed Ismail, Department of Medical Laboratory and Parasitology, Faculty of Applied Medical Science, Taif University, Taif, Saudi Arabia

\begin{abstract}
Foodborne diseases outbreaks continue to be problem indicating the failure of population to adhere to safe practices during food preparation. Thus, this study aimed to assess the knowledge, attitude, and practices (KAP) of food safety awareness among public Saudi population. This study involved 136 persons from Taif Saudi Arabia. The food safety KAP among 136 Saudi population was assessed using a questionnaire. The study involved $54.4 \%$ females and $45.6 \%$ males, $56.6 \%$ work outside health field and $43.4 \%$ in health care field ,82.4\% from urban area and $17.6 \%$ from rural area and $81 \%$ within the age group from $21-30$ years old. $75.7 \%$ of the population had good attitude and practice towards health and food safety and washing hands before eating. Further population had low attitude on other related items such as unimportance of reading the instruction label on the canned food 59.5\%, unimportance of checking the refrigerator temperature $77.9 \%$, and unimportance of changing the cutting knife used between meat and vegetables cutting $66.9 \%$.

As regard knowledge, $61.8 \%$ of population had good knowledge about best temperature for bacterial growth which is between 4 to $50{ }^{\circ} \mathrm{C}$ and about $73.5 \%$ of population had good knowledge about diseases that could be transmitted through food. but only $27.2 \%$ of population had knowledge about suitable method of meat thawing. In conclusion, the suggestion of this study was that Saudi population had adequate food safety knowledge, but perceived knowledge failed to be translated into practices, therefore necessary to hold training programs through workshops or to include courses in the curriculum of ministry of health.
\end{abstract}

Keywords: Food Safety; Knowledge; Attitude; Practice

\section{Introduction}

The World Health Organization (WHO) reports that there approximately 2 million cases of food poisoning occur every year globally [1], especially in developing countries. This could be due to the poor state of food safety and general hygiene in those countries [2]. More than $50 \%$ of the total food poisoning cases were attributed to improper food handling [3]. Food-borne diseases have increased over the years, and dangerously affected the health and economic well-being of many developing countries [4]. Food poisoning occurs as a result of consuming food contaminated with microorganisms or their toxins, the contamination arising from inadequate preservation methods, unhygienic handling practices, cross-contamination from food contact surfaces or from persons harboring the microorganisms in their nares and on the skin $[5,6]$. Unhygienic practices during food preparation, handling and storage creates the conditions that allows the proliferation and transmission of disease causing organisms such as bacteria, viruses, parasites and other food-borne pathogens $[7,8]$.
Poor personal hygiene, primarily ineffective hand washing, has been recognized as a significant risk factor of food contamination that leads to food poisoning $[9,10]$. Hand hygiene is the most basic critical criterion for ensuring safe food handling. In fact, hand washing has long been known to be a fundamental precautionary measure in health care settings [11], as well as in the kitchen for preventing the spread of infectious disease through human to human or human to food contact [12-15]. Foods such as meat could be regarded as a high-risk food owing to their abundant ingredients that could favor the growth of microorganisms [16]. The foods most frequently involved in disease outbreaks are those of animal origin, particularly beef, poultry, pork, milk, fish, and eggs [17]. There is a strong relationship between meat consumption and foodborne disease outbreaks [18].

The US Centers for Disease Control and Prevention revealed that every year there could be outbreaks of foodborne diseases that might have resulted from foods of animal origin, causing about 
76 million illnesses, 325,000 hospitalizations, and 5,000 deaths per year [19]. Still little efforts are being made, especially in the developing countries, to address these public health challenges. There is little information about the true level of exposure of specific populations to potential hazards, especially in the case of bacterial diseases that are transmitted by consumption of meat and meat products [20]. Food contamination involving food poisoning has raised alarm in Saudi Arabia. During the past ten years, a number of incidents of food borne outbreaks were reported in some regions. In 2006, during the annual Hajj pilgrimage, a group of Saudi soldiers were diagnosed for having gastroenteritis following a rice lunch contaminated with Bacillus cereus and Clostridium perfringens. In 2007, Najran city registered 92 cases of food poising outbreaks. Similar outbreaks occurred in some other parts of Saudi Arabia like, Al-Hofuf, Sulyyel, a town near Riyadh in 2010 and Qassim House of Social Education in 2011. Different sources of infections were reported following the outbreaks. In a crosssection study conducted around a catchment area involving seven primary health care centers, food handlers, specifically raw food handlers of certain nationalities, were found to be the major source of food contamination. A cross section study was conducted in Jizan city to ascertain the knowledge and practices of street vendors. The results obtained showed low to middle level of KAP among them. In Jeddah, butchers were found to be mainly involved in contamination practices. Critical food control infractions and fraud have been repeatedly spotted at restaurants inspected in different parts of Saudi Arabia [21].

The outbreak an incident of food poising occurred in Taif city in 2006 when an extended family reported to the hospital with gastroenteritis symptoms. 39 of 64 members of the family were found sick of which one patient died within three days of the incident. The outbreak was attributed to Escherichia coli, which was isolated from raw milk [22]. Furthermore, there was little or no information available on the level of food safety Knowledge, Attitude and Practice (KAP) regarding compliance within population. Therefore, these could help in the development of appropriate disease prevention and public health intervention strategies. Hence, the present study was designed to assess the food safety KAP among general population in Taif Saudi Arabia.

\section{Subjects and Methods}

This descriptive study was conducted on one hundred and thirty-six person. Structured questionnaire was prepared to collect information on the knowledge, attitudes and practices of public population on food safety. Data was collected in January 2018. The questionnaire was structured into three distinctive sections. Section one and two were concerned with information on general population knowledge of food safety, attitude towards food safety and food hygiene practices respectively. Section three was to collect information on general population demographic characteristics such as gender, age, residence and occupation. The section of questionnaire dealing with food safety knowledge comprised 9, 6 of them are close-ended questions with three possible answers; "true", "false" and "I do not know". And 3 scientific questions. These questions specifically dealt with general population knowledge about diseases transmitted by food consumption, symptom of foodborne diseases, suitable temperature for microorganism's growth and hygienic practices. As regard questions about attitudes and practice were aimed at determining the understanding of public population about food safety and application of this understanding . This section had 7 frequency questions that required four possible responses: "always", "often", "sometimes" and "rarely".

\section{Statistical Analyses}

The Statistical Package for Social Science (SPSS) for Windows (version 22.0, Chicago, IL) was used for analyses of data.

\section{Ethical Considerations}

Ethical approval for this study was obtained from the Ethics Review Committee of the College of Applied Medical Sciences at Al-Taif University. Moreover, all participants included in the study were informed of the study objectives and a written signed consent was taken from each one of them.

\section{Discussion}

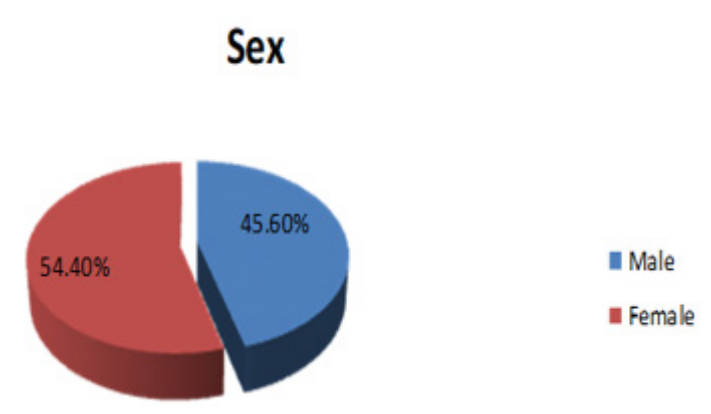

Figure 1: Sex distribution among study group.
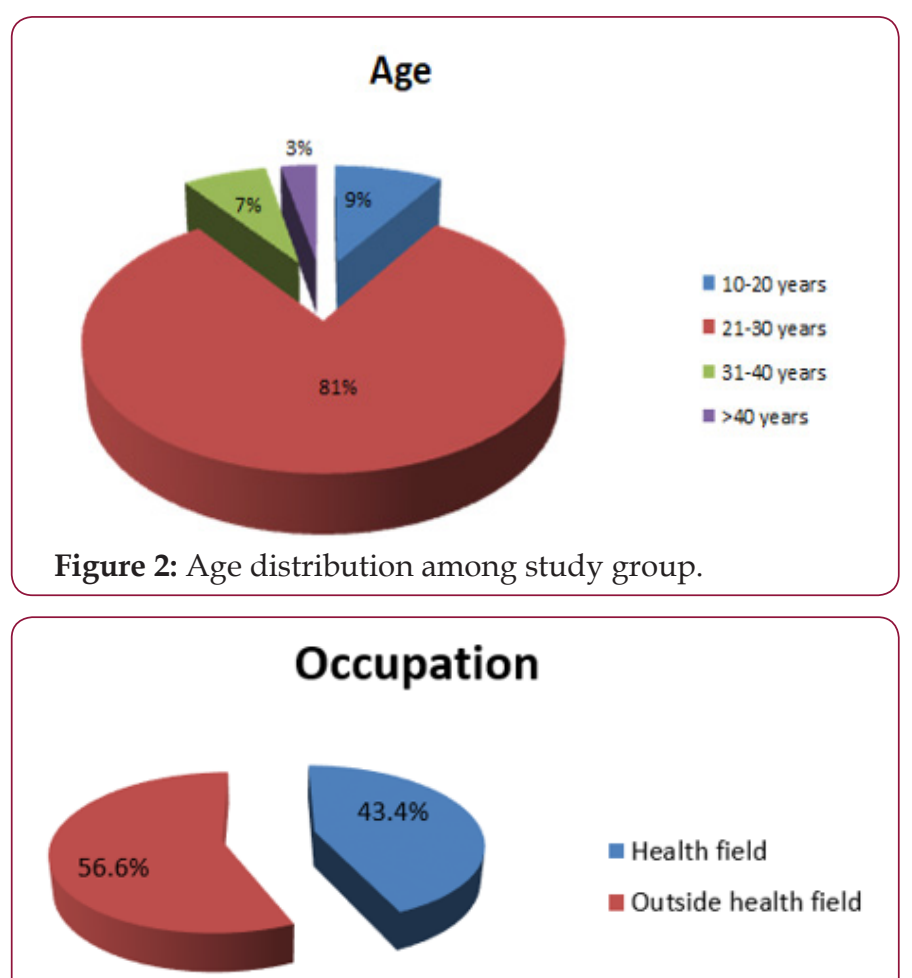

Figure 3: Occupation distribution among study group. 


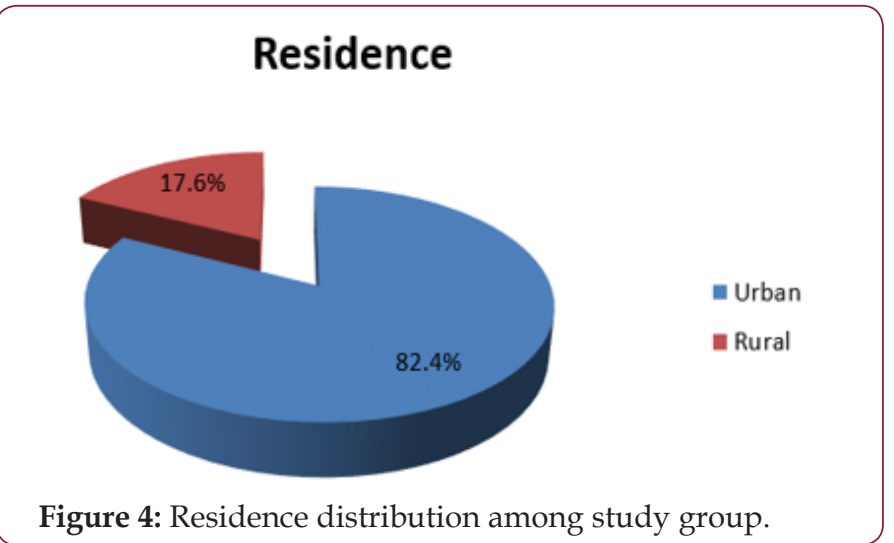

One hundred and thirty-six (136) participants responded to food safety survey questionnaire. Figures 1-4 show respondent's demographic profile such as their gender, age group, nature of work and area of residence. It is seen that percentage of male and female respondents are about $45.6 \%(62 / 136)$ and $54.4 \%(74 / 136)$, respectively. Furthermore, maximum number of respondents (81\%; 111/136) are found to be in the age group 21-30 years. Least number of respondents $(3 \% ; 4 / 136)$ belongs to age group more than 40 years. It is also seen that majority of the participants belong to urban population $(82.4 \% ; 112 / 136)$ as compared to rural residents $(17.6 \% ; 24 / 136)$. As far as occupation is concerned, there is not a major difference seen in number of respondents that turned up; health field workers account for 43.4\% (59/136) and non-health field occupations make up to a total of 56.6\% (77/136). Figures 5 - 13 illustrate the response of the participants to questions related to food safety knowledge.

\section{Food poisoning is caused by pathogenic microbes only}
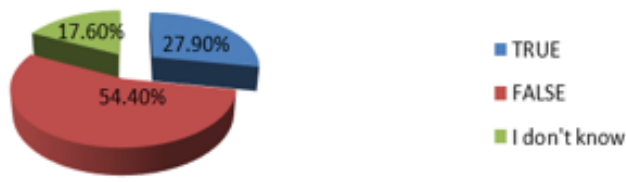

Figure 5: Distribution among study group of knowledge about food poisoning cause.

Note: Food safety knowledge.

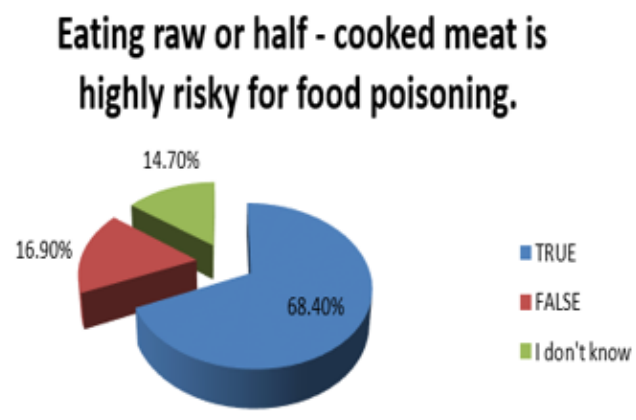

Figure 6: Distribution among study group of knowledge about hazard of raw meat consumption.

\section{Keeping food at refrigerator temperature helps to prevent food poisoning.}

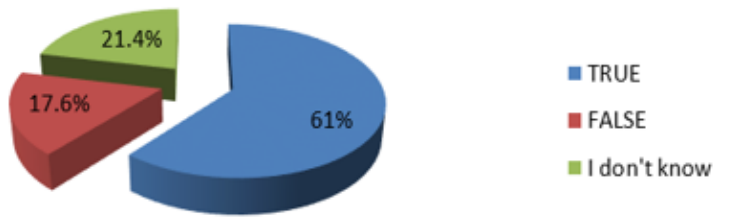

Figure 7: Distribution among study group of knowledge about refrigerator can prevent food poisoning.

\section{The correct method for thawing frozen meat is to keep them overnight at room temperature.}

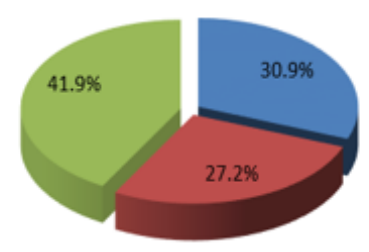

- TRUE

- FALSE

EI don't know

Figure 8: Distribution among study group of knowledge about correct way of thawing frozen meat.

\section{Insects such as cockroaches and flies might transmit foodborne pathogens.}

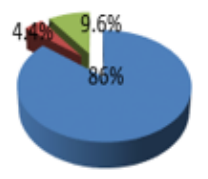

Figure 9: Distribution among study group of knowledge about correct way of thawing frozen meat.

\section{Microbial growth is faster in summer than winter.}
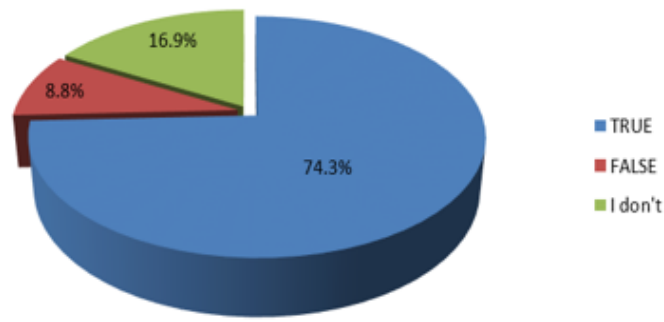

m FALSE

$=$ I don't know

Figure 10: Distribution among study group of knowledge about the season of more microbe's growth. 


\section{Which of the following diseases can be transmitted by ingestion of contaminated foods?}

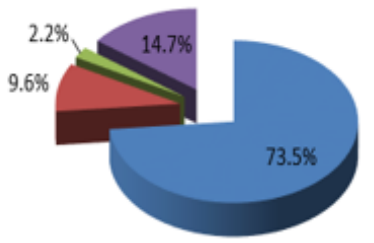

- Hepatitis A

- Pnemonia

$=\mathrm{AIDS}$

॥ Flu

Figure 11: Distribution among study group of knowledge about the disease transmitted by food consumption.

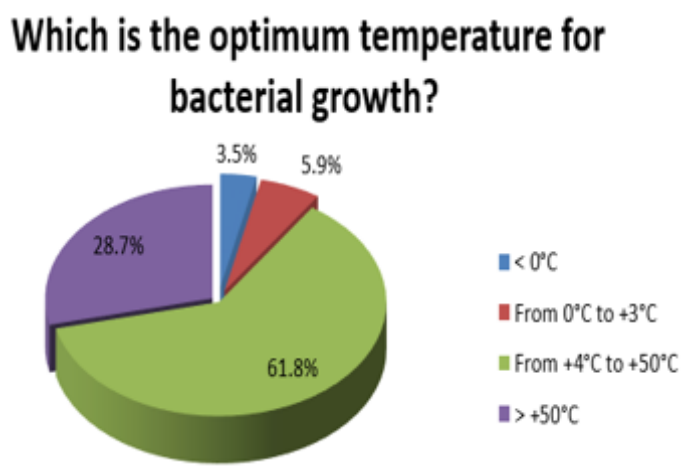

Figure 12: Distribution among study group of knowledge about optimum temperature for microbe's growth.

\section{Which of the following are caused by food intoxication?}

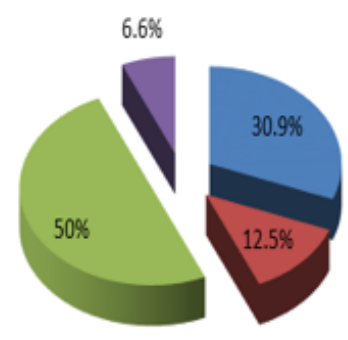

\author{
Vomit, diarrhea, fever \\ Enly vomit and diarrhea \\ It depends on the type of \\ causative germ \\ mever, sore throat and cough
}

Figure 13: Distribution among study group of knowledge about symptom of food poisoning.

Only $27.90 \%$ (38/136) respondents knew that food poisoning is caused by pathogenic microorganisms alone. Ninety-three (93) participants corresponding to $68.4 \%$ know consuming raw or half-cooked meat is risky for health of consumers. $61 \%(83 / 136)$ and $27.2 \%(37 / 136)$ of the participants responded correctly to items such as prevention of food poisoning by refrigerating food. Out of 9 knowledge testing questions, maximum correct response is found to have come up for items like insects transmitting foodborne pathogens $(86 \% ; 117 / 136)$ and microbial growth being faster in summer season $(74.3 \% ; 101 / 136)$. Another item where high number of respondents answered accurately is related to diseases transmitted by ingestion of contaminated foods for which
$73.5 \%$ opted for hepatitis-A. A high score is also seen for item such as optimum temperature needed for bacterial growth $(61.8 \%$ answered correctly). These high number of correct responses are appreciable even though most of them are non-health field occupation's.

It sheds light on the fact that local residents of Taif city are knowledgeable about the facts related to food safety and hygiene. As far as knowledge of signs and symptoms caused by food intoxication is considered, $50 \%$ managed to give a correct answer; for which they answered that it depends on the organism. However, remaining 50\% gave incorrect answer out of which $6.6 \%(9 / 136)$ say that fever, sore throat and cough are caused because of food intoxication. This could be due to the fact that higher number of survey participants occupation is outside the health field as compared to health field occupation's. So, they are not much aware of the signs and symptoms caused by pathogenic microorganisms. For items number 5-11 with options such as "true", "false" and "do not know", the percentage of respondents who did not know the correct answer varies between $9.6 \%$ to $41.9 \%$. Overall, the mean percentage of correct entries among the surveyed population is $57.5 \%( \pm 24.6)$, whereas the mean percentage of incorrect entries is found to be $22.2 \%( \pm 18.2)$.

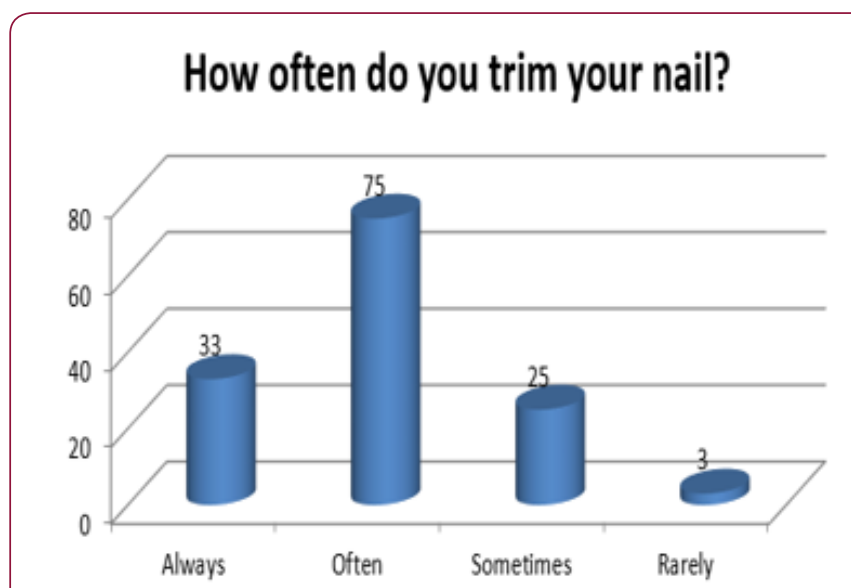

Figure 14: Distribution among study group of attitude and practice about trimming nail.

Note: Food safety attitude and practice.

\section{How often do you cut raw vegetables and meat by the same knife?.}

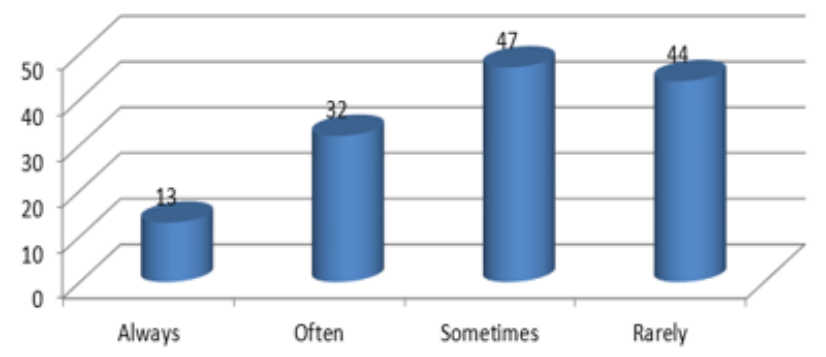

Figure 15: Distribution among study group of attitude and practice about cutting meat and vegetables with the same knife. 


\section{How often do you wash your hands before handling food?}

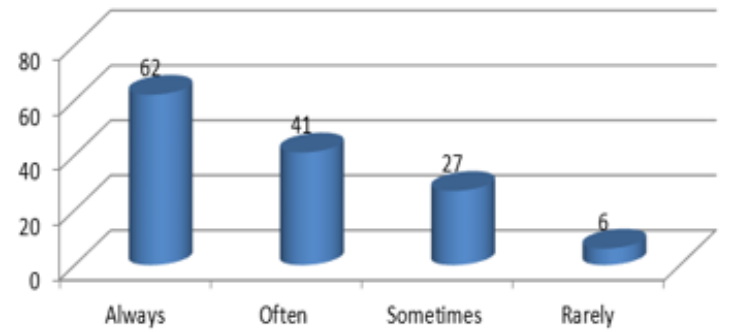

Figure 16: Distribution among study group of attitude and practice about washing hand before handling food.

\section{How often do you check the temperature of the refrigerator?}

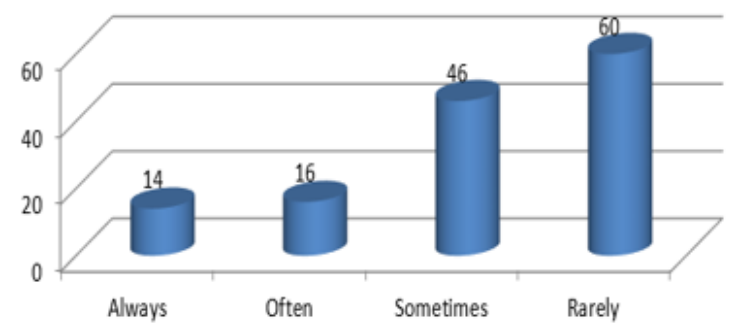

Figure 17: Distribution among study group of attitude and practice about check of refrigerator temperature.

\section{How often do you read the expiry date before purchasing food items?}

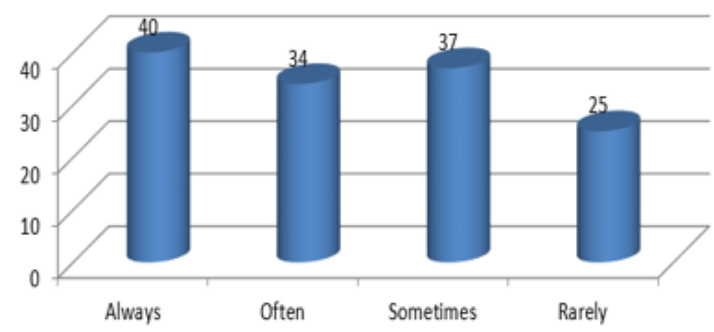

Figure 18: Distribution among study group of attitude and practice about reading the expiry date of food items.

The remaining percentage of respondents who do not know the correct answer is $20.4 \%( \pm 11.2)$. The food safety attitudes and practice of all the respondents has been shown in Figures $14-20$. The response to these survey questions are answered as "always", "often", "sometimes" and "rarely". All these items relate to the frequency of attitudes and good practice in context of food safety, such as trimming nails, cutting raw vegetables and meat using same knife, washing hands before handling food, checking temperature of refrigerator, reading expiry date before purchasing food items, reading instructions written on packaged foods and frequency of eating raw eggs. The results found are not so encouraging as far as food safety attitude and practice is concerned. Maximum number of responses in favor of good attitude and practice are found in only two of the seven items; always or often trimming nails (79.4\%) and washing hands before handling food (75.7\%); others show a very low score. On an average, considering all the seven items, only $50.9 \%$ of survey respondents show good attitude towards food safety. The remaining $49.1 \%$ respondents are only "sometimes" or "rarely" considerate over good practice.

\section{How often do you read the instruction for use and for preservation written on the packaged foods?}

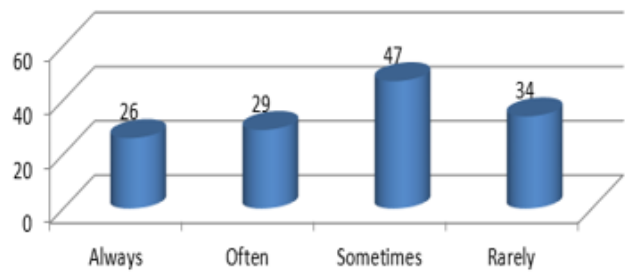

Figure 19: Distribution among study group of attitude and practice about reading the instruction on packaged food.

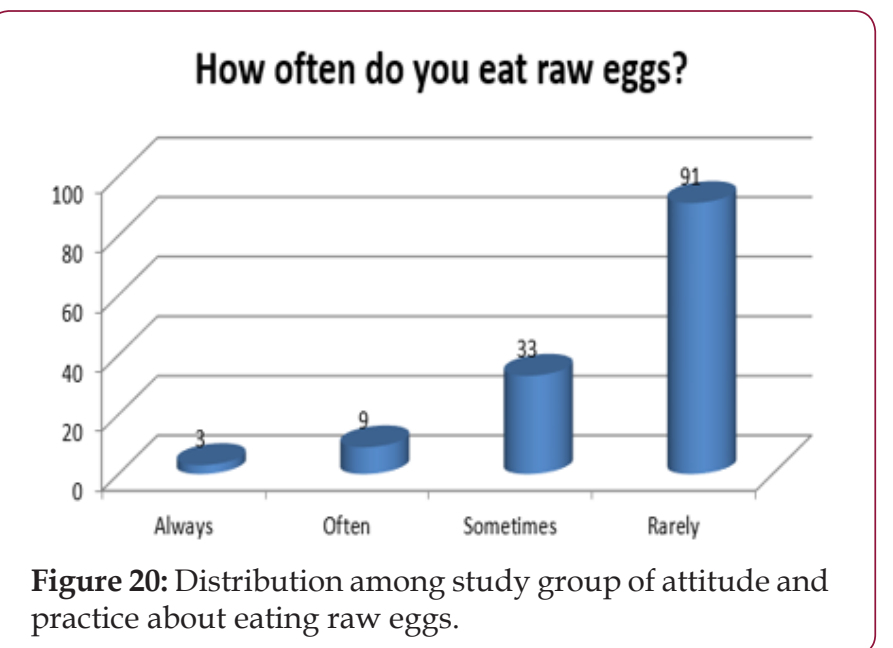

The response of consumption of raw eggs is somewhat appreciable as $91.2 \%$ show a favorable response. It is seen from the mean percentages that there is not a major difference between right food safety knowledge (57.5\% correct responses) and good attitudes and practice for food safety (50.9\%) among all the survey participants. Food-borne diseases, an increasing public health problem, are causes for worldwide morbidity and mortality. Different types of pathogens are the main cause of more than 250 food borne diseases $[23,24]$. In Saudi Arabia, food poisoning is becoming a very serious health issue [25]. Food may be mishandled during storage, during preparation or before its consumption at home, thus leading to cross-contamination and microbial growth in food. These situations can be brought under control if consumer have the necessary knowledge for prevention. Therefore, awareness of consumers regarding proper food handling as well as good cooking practices is imperative [26]. It is seen in this study 
that almost half of the respondents have a good knowledge about food safety.

They are aware that eating raw or half-cooked meat is highly detrimental to one's health and that refrigeration helps in preserving the integrity of food, thereby preventing food poisoning. They also know well that microbial growth is faster in summer season due to optimum temperature necessary for microbial growth; and that some insects may be a potential source of transmitting food-borne pathogens. Furthermore, there were variations among the respondents in answering correctly in both knowledge, their attitudes for food safety and practice of personal hygiene such as trimming nails and washing hands before handling food. Therefore, they need to increase their awareness in these domains, in the light of their responses. In conclusion, the results of this study shed light on the fact that food consumers in Saudi Arabia should view mishandling of food as a direct threat to their health. This necessitates launching a food safety training program from the responsible authorities emphasizing all food safety parameters.

\section{Limitations of the study}

One of the limitations of this study is the small sample size. The results would be more conclusive with an optimal sample size. Another limitation is that food safety attitudes and practice were assessed through self reporting method and the conclusion drawn could be overestimation of actual practices.

\section{Acknowledgment}

Authors acknowledge the valuable assistance provided by Miss Asmaa Mahmoud Khalifa, news editor for her tremendous help and support to finalize this research study.

\section{References}

1. (2015) World Health Organization (WHO) Food Safety. WHO, Geneva, Switzerland.

2. (2014) Ministry of Health (MOH) Health Facts 2014. MOH, Putrajaya, Malaysia.

3. (2007) Ministry of Health (MOH) Annual Report 2007. MOH; Putrajaya, Malaysia.

4. (2007) WHO Food Safety and Foodborne Illness. Fact sheets No.237 Geneva World Health Organization.

5. Barrie D (1996) The provision of food and catering services in hospital J Hosp Infect 33(1): 13-33.

6. Jay LS, Coma D, Govenlock LD (1999) A video study of Australian domestic food-handling practices. J Food Prot 62(11): 1285-1296.

7. Fielding JE, Aguirre A, Palaiologos E (2001) Effectiveness of altered incentives in a food safety inspection program. Prev Med 32(3): 239244.

8. Gent RN, Telford DR, Syed Q (1999) An outbreak of campylobacter food poisoning at a university campus. Commun Dis Public Health 2(1): 3942.
9. (2002) Scarborough MF Master's Thesis, Emory University, Hand Washing in Georgia's Public Schools-A Community Needs Assessment and Intervention Study, Atlanta, GA, USA.

10. Curtis V, Cairncross S (2003) Effect of washing hands with soap on diarrhea risk in the community: A systemic review. Lancet Infect Dis 3(5): 275-281.

11. World Health Organization World Health Organization. Evidence of hand hygiene to reduce transmission and infections by multidrug resistant organisms in health-care settings. In Clean Care is Safer Care Team, editor. WHO Guidelines on Hand Hygiene in Health Care. WHO, Geneva, Switzerland.

12. Gibson LL, Rose JB, Haas CN, Gerba CP, Rusin PA (2002) Quantitative assessment of risk reduction from hand washing with antibacterial soaps. J Appl Microbiol 92(1): 136-143.

13. Chinakwe EC, Nwogwugwu NU, Nwachukwu IN, Okorondu SI, Onyemekara NN, et al. (2012) Microbial quality and public health implications of hand-wash water samples of public adults in Owerri, South-East Nigeria. Int Res J Microbiol 3(4): 144-146.

14. Soares LS, Almeida RC, Cerqueira ES, Carvalho JS, Nunes IL (2012) Knowledge, attitudes and practices in food safety and the presence of coagulase positive staphylococci on hands of food handlers in the schools of Camaçari, Brazil. Food Control 27(1): 206-213.

15. Perez Rodriguez F, Valero A, Carrasco E, Garcia RM, Zurera G (2008) Understanding and modelling bacterial transfer to foods: A review. Trends Food Sci Technol 19(3): 131-144.

16. Subratty AH, Gurib FB (2003) Consumers' concern about the meat product quality offered for sale in Mauritius. Nutrit Food Sci 33(2): 8083.

17. Bean NH, Goulding JS, Lao C, Angulo FJ (1996) Surveillance for foodborne disease outbreaks - United States, 1988-1992. MMWR CDC Surveill Summ 4(5): 1-66.

18. Holt G, Henson SJ (2000) Quality assurance management in small meat manufacturers. Food Control 11(4): 319-326.

19. Aluko 00, Ojeremi TT, Olaleke DA, Ajidagba EB (2014) Evaluation of food safety and sanitary practices among food vendors at car parks in Ile-Ife, southwestern Nigeria. Food Control 40: 165-171.

20. Otsuki T, Wilson JS, Sewadeh M (2001) Saving two in a billion quantifying the trade effect of European food safety standards on African exports. Food Policy 26(5): 495-514.

21. Bakri M, AL Amin F, Saleh A, Saeed A, Nabag M, et al. (2017) Food hygiene in past ten years in Saudi Arabia. EC Microbio 7(1): 4-13.

22. Al Mazroua M, Al Hamadan N (2006) Foodborne outbreak among 4 families in Taif city, Saudi Arabia. Epidemio Bulle 13(4): 28-31.

23. Fleury MD, Stratton J Tinga C, Charron DF, Aramini J (2008) A descriptive analysis of hospitalization due to acute gastrointestinal illness in Canada, 1995 - 2004. Can J Public Health 99: 489-493.

24. Linscott AJ (2011) Food-borne illnesses. Clini Microbio Newsletter 33(6): 41-45.

25. EL Sheikha A (2015) Food safety issues in Saudi Arabia. Nutr Food Techno 1(1).

26. Medeiros LC, Hillers VN, Kendall PA, Mason A (2001) Food safety education: What should we be teaching to consumers? J Nutr Educ 33(2): 108-113. 
ISSN: 2574-1241

DOI: $10.26717 /$ BJSTR.2018.08.001629

Khadiga Ahmed Ismail. Biomed J Sci \& Tech Res

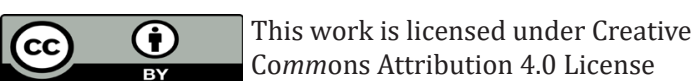

Submission Link: https://biomedres.us/submit-manuscript.php

Assets of Publishing with us
BIOMEDICAL
RESEARCHES

